\title{
OPEN
}

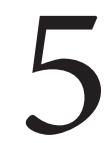

\section{Doing Cross-European Technology Assessment}

\author{
Marianne Barland, Danielle Bütschi, \\ Edgaras Leichteris and Walter Peissl
}

Abstract: The authors give a case-based state-of-play account of cross-European TA cooperation in service of national parliaments as well as the European Parliament. Most TA units have formed their role around the specific needs of their national or regional parliaments and other national or regional target groups, making it challenging to shift focus and create new roles for themselves in a European sphere. This article presents recommendations on how cross-European TA can be done in the future with a focus on three aspects of cross-European TA: (1) the added value of cross-European work and lessons from past experiences; (2) the identification of efficient and credible modes of cooperation to conceptualize cross-European TA; (3) the identification of relevant target groups and addressees and the bringing about of impact on the European level.

Klüver, Lars, Rasmus Øjvind Nielsen, and Marie Louise Jørgensen, eds. Policy-Oriented Technology Assessment Across Europe: Expanding Capacities. Basingstoke: Palgrave Macmillan, 2016. DOI: 10.1057/9781137561725.0014. 
As a consequence of globalization and European integration, politics is moving upwards, and policy making on many science- and technologyrelated issues needs a cross-border approach. However, when we look back at the history of European TA, the development and use of technology assessment has been characterized by national and regional efforts, with little capacity for doing cross-European work. As the EU grows, and all European countries become more connected, cross-European TA can contribute to knowledge exchange and capacity building between countries and regions - and as a result provide robust and independent policy advice for European policy makers as well as other traditional target groups in the national context. Issues related to science and technology are often discussed at a European level, and it seems only natural that these discussions should inform each other and contribute to a broader knowledge base for decision making - whether on a regional, national or European level. The PACITA project, therefore, aims at encouraging practices of cross-European TA in order to strengthen the knowledge base for policy making in Europe.

In this chapter, we discuss the challenges of doing cross-European TA in practice and the framework conditions for using TA transnationally at the European level. In the introduction to this book, we have seen how cross-European TA may fit within existing frameworks for European cooperation. This chapter supplements the introduction by providing an 'on-the-ground' account of the practical and organizational work that it takes to carry out TA projects in trans-European cooperation. We base our discussion on case studies of previous cross-European projects and on new experiments carried out within the PACITA project, all of which have produced important insights on the added value of cross-European TA and how it may be done in the future. These insights show the diversity and inclusiveness which have become characteristic for cross-European projects. Cooperation and communication across borders not only provide knowledge exchange but create arenas and networks for knowledge production and policy learning among European member states and European institutions. Participation in cross-European projects will therefore benefit society's ability to comprehend issues related to science and technology and at the same time open up the process of policy making, making it more understandable and accessible for European citizens. Our findings, however, also show that cross-European TA has so far been conducted on a project-by-project basis, which means that new cooperation forms and capacities have to be established for each 
project. There is therefore a need to develop a European platform that would ensure support for cross-European projects, with regard to both financial and human resources.

\section{Cross-European technology assessment: current situation}

Several research projects and reports have documented the activities and methods of TA in Europe, ${ }^{1}$ but few of these have discussed cross-European cooperation and how this can be done in the best possible way. The PACITA project had a goal of making recommendations for the future of cross-European TA, based on lessons learned from past examples of cross-European projects as well as research done in the PACITA project.

Although a STOA report (Enzing et al., 2012) from 2012 describes cross-European TA as limited, there have been several European and international TA projects over the years. Experiences and lessons learned from these projects give important input for further development of work modes, methods and funding schemes. The PACITA project has conducted a number of case studies with the aim of identifying the added value of the cross-European approach, as well as identifying some of the barriers and challenges related to these types of projects.

The EPTA (European Parliamentary Technology Assessment) network is an example of an existing network of European PTA units. Together, the partners of EPTA aim at making TA an integral part of policy consulting in parliamentary decision-making processes around Europe. EPTA has initiated and organized several cross-European projects. These projects ${ }^{2}$ are always funded on the partners own budget, as the network itself does not have any resources. This funding scheme creates certain limitations in the project design, and the method in EPTA projects has over the last years been limited to distributed desktop research, in which all partners write a state-of-the-art chapter from their country/region on a given topic and present policy options. The contributions are then collected and presented in a common report, opened by a short introduction written by the project coordinator. There is rarely any in-depth cross-European analysis of the national contributions, but taking their minimal resources into account, these projects have a good record of accomplishment. Feedback on the joint EPTA projects shows that parliamentarians appreciate seeing how other countries deal with the same challenges as themselves. 
Another type of projects is funded through the European Union's Framework Programs, ${ }^{3}$ like the PACITA project. The projects are based on project calls from the European Commission and cover a broad spectrum of topics. These projects have dedicated budgets that make it easier to use more demanding methods than the EPTA projects. This can include methods that involve citizens or stakeholders in addition to more traditional desktop research. A consortium in these projects often involves several types of partner institutions (universities, NGOs, research institutes, TA institutions etc.).

A third type of project ${ }^{4}$ is commissioned by STOA (the TA unit of the European Parliament) and carried out by members of European Technology Assessment Group (ETAG) or other consortia. These projects have both a dedicated budget and pre-defined target group in STOA. The projects cover a variety of topics and use mostly desktop research and expert hearings as methods. One challenge with commissioned projects is that it can be difficult to identify the most relevant scope for policy makers when taking on topics where extensive research has already been done. That the project is scientifically 'less free' when the project is commissioned by a 'client' can also be challenging.

\section{The PACITA experience}

From the pool of previously conducted TA projects, there are several types of projects and consortia which differ with regard to funding schemes, methods, target groups and project designs. PACITA organized three example projects, aiming to produce relevant policy advice at national, regional and European levels. The projects also aimed at enhancing the capacity of technology assessment in Europe by including both experienced institutions and 'newcomers' in the field of TA. On a more practical side, the projects functioned as an introduction and as training for TA practitioners involved in the PACITA project.

The three example projects took on three of the Lund declaration's 'grand challenges', using different methods and involving different types of actors:

While scenario workshops and citizen summits are quite established methods at the European level, it was the first time that the Future Panel was used in a cross-European manner. This 'methodological experiment', together with the two more established methods, has given important 
TABLE 5.1 Overview of PACITA example projects

\begin{tabular}{lll}
\hline Topic & Method & Involved actors \\
\hline Personal health genomics & Future Panel & Parliamentarians and experts \\
The future of ageing & Scenario workshops & Stakeholders \\
Sustainable consumption & Citizen summits & Citizens \\
\hline
\end{tabular}

insights on how to organize successful cross-European TA projects (see Part II of this book).

One of the challenges related to the Future Panel method, was the need for long-term commitment by parliamentarians. Earlier experiences with the Future Panel method on the national level have involved parliamentarians who have been appointed to the Future Panel by their parliament (Krom and Stemerding, 2014). A more direct link to the national parliaments (and not only involvement of individual parliamentarians) makes a clearer mandate for participation in the project, and it will probably make it easier for parliamentarians to commit to the project. The two other example projects had a single national event as the main activity. The activity demanded some preparation by the participants (reading information material or scenarios), but it demanded no long-term commitment to the project.

One might argue that by doing such national events, the crossEuropean element is put in the background. But seeing that both the citizen summit and the scenario workshop had a common European starting point for the discussions, ${ }^{5}$ the participants still got the feeling of being part of a European project. Knowing that there are others having the same discussions, following the same method, somewhere else in Europe was acknowledged and appreciated by the participants. In miniature, the deliberative fora that were created within the projects seemed to engender an experience of European citizenship solidly rooted in national communities. The results from these national events were gathered in European synthesis reports, bringing the results from the national to the European level.

In addition to the policy recommendations produced by all three example projects, an important result is the added value for the TA community. Focus on method training gives all of the involved partners a strong foundation to further use these methods also after the end of the PACITA project, and it enhances the capacity of the involved institutions. 


\section{Barriers to cross-European TA}

Although there have been a number of cross-European projects that have been conducted over the years (as described above), one cannot speak of regular cross-European TA having been done.

\section{National vs European commitments}

However, a tension might occur for each individual organization between doing national projects and participating in European projects. This tension may act as an obstacle for developing cross-border collaboration. Easing this tension might be a factor that can lower the threshold for TA institutions to engage in cross-European TA. Most of the existing TA institutions have their mandate mainly focused on the national and regional spheres. Some have an identified task to 'watch trends in science and technology' (on both the national and the international level) (Ganzevles and Van Est, 2012), but none have international cooperation as a defined task. Identifying and understanding the added value in cross-European projects may help to open up and stimulate more cooperation and at the same time justify international cooperation with regard to mandates and resources, without stealing attention away from national working plans.

\section{Finding a European audience}

One of the main characteristics of the traditional TA units has been their strong connection to parliaments (see also Chapter 1). This relationship has often been institutionalized either by organizing the unit inside parliament or by stating this relationship in the mandate of the institution. Some 40 years later, the audience of TA or TA-like institutions is wider and includes all actors involved in policy making - that is, members of parliament, but also governmental representatives, civil society and even the scientific community. However, these actors are mainly nationally based, showing that the audience of TA lies within usually national (or regional) frontiers.

When TA activities take place at the European level, it becomes more difficult to create permanent relationships with addressees and potential target groups than in national projects. In national contexts, there exists a defined public sphere, although there is no clearly defined 'European public'. One possible approach is to have a broader view of addressees and 
target groups when working at the European level than at the national/ regional level. If the goal of TA is to give input for evidence-based decision making, it might help to widen the definition of who decision makers in fact are. In the European context, the European Commission and the European Parliament play important roles as policy makers. But Europe is multifaceted and consists not only of the European Union; many others (lobbyists, NGOs and the media) take part in decisions and hold power in important discussions about the policy issues and options. Therefore, all those organizations and institutions can be potential target audiences for cross-European TA, on the European as well as the national level. Nations are an important part of, and often the operative level, European policy making. They should, therefore, also be an addressee of cross-European project results. In order to reach such an audience, focus should be on communication efforts and on forming clear and targeted policy advice.

One important audience is the TA community itself. Results from successful cross-European projects can be used at the national level from institutions not involved in the specific project and also as an encouragement for participation in future cross-European work. This would contribute to a bigger pool of evidence of cross-European work - hence raising the legitimacy and the trust in a cross-European approach and in TA methods.

\section{Benefits of cross-European TA}

Based on the challenges related to European projects, it is important to identify the defining elements of cross-European TA and to understand what makes technology assessment an important contributor for policy advice in Europe.

\section{For society}

The emerging technologies debated in different countries are more or less the same. But contexts and timing of discussions, and the shaping of technologies, will differ nationally. Thus, cross-European TA can contribute to agenda setting and provide policy support at the European level and at the same time inform national science and technology discourse. This has already been identified in the area of European science policy, moving from 'science in Europe' to 'European science' (Nedeva and 
Stampfer, 2012). Focus has moved from coordination of national projects to the development of a more integrated, pan-European science base. When topics are relevant across borders, it's reasonable to think that it would be more effective to make projects on a cross-European basis rather than have every TA unit do similar projects in their country/ region.

\section{For parliaments}

In the 1970s, when TA started to get institutionalized in Europe, the influence of the American tradition of TA was evident. However, as argued by Norman J. Vig (2000), the European approach to TA turned out as more of a democratic project than it had been in the US, where the focus had mostly been on creating an informed policy debate on science and technology issues. Introducing TA in the diverse and culturally varied Europe, TA became a strong instrument in the democratic process, providing independent and thorough advice for parliaments, based on participation of a broad group of actors. This is also one of the reasons for the survival of these organizations, Vig argues: they have proved useful for parliaments.

\section{For TA institutions}

PACITA is in itself a good example of how TA institutions benefit from doing cross-European projects. PACITA strengthened the ties between the existing TA units, and it also helped establish a strong base for further institutionalization of new initiatives in Europe. Doing PACITA's three example projects proved that participation in cross-European projects is highly productive from a practitioner's point of view. The cooperation provided institutional learning and an exchange of experience between TA practitioners, and the hands-on experience from the projects created enthusiasm for TA both among the participating institutions who were new to the field and among the policy makers who received the results.

\section{Requirements for realizing cross-European TA}

An essential element of TA is the notion of independence. This refers to the independence of TA institutions from stakeholders' interests and influence, as well as the independence from funders and policy makers 
themselves. Independence is important to maintain the TA institution's credibility, and it will strengthen the reputation of TA in Europe at a more general level. Giving well-founded and independent advice is one of the main strengths of TA, compared to policy advice from NGOs and lobby groups, who have their own interests in mind.

Future cross-European TA initiatives should be both inclusive and diverse. Acknowledging that others see similar challenges but deal with them differently can lead to knowledge and new perspectives. CrossEuropean TA can contribute to agenda setting and policy support at the European level and at the same time inform national science and technology discourses. The PACITA project had a variety of partners, not only traditional PTA institutions. The diversity of the consortium combined with the cultural backgrounds of the countries and regions involved created a learning process for all partners - and contributed in new knowledge production for policy makers. However, there will always be challenges related to cross-European participation and national financing. Seeing that the financial situation of the different national and regional institutions varies, it is difficult to ensure the diversity of TA on the European level.

In the last few years, the field of TA has changed. Several institutions have been transformed and reorganized, and one can see a need to broaden the scope of European TA, from purely parliamentary TA (PTA) to forms of TA that approach policy making in a broader way. PACITA's efforts in expanding TA throughout Europe highlight the democratic approach to TA that is taken in Europe, and the introduction of TA in new countries, regions and cultures will add value to policy makers and the TA community. A more permanent and stable presence of TA at the European level also will serve as important support for TA initiatives in the future.

Creating a permanent and stable presence of TA on the European level, and making it easy and desirable for TA institutions to participate in cross-European projects, demands more systematic funding than is provided today. The experiences from previous TA projects might seem to argue that as long as there are funding mechanisms available, such as the EU framework programmes, then cross-European TA will continue to exist. However, there is a strong belief that cross-European TA can grow even stronger if there is more systematic financing for crossEuropean cooperation, which is not limited to individual projects. A continuous presence, such as in the format of a TA Platform, will make 
a stronger impact than individual national institutions coming together for projects now and then (see also Part III of this book).

There has been an increase in cross-European initiatives in the field of TA. This is reflected in the number of projects, the number of participants and the involvement of new countries and institutions. The TA community in Europe has historically been oriented towards producing policy advice for national and regional parliaments. Because of the shifting landscapes in Europe, it makes sense to extend the addressees to a wider group of policy makers. This move will give greater opportunities for making an impact in a wide range of policy processes. At the same time, it will open the field of TA to participation of a broader group of institutions, not only the 'traditional' institutions doing parliamentary technology assessment. A variety of institutions are now active in the field of TA in Europe. They all have to find their own strategies for how to be agile and flexible enough to participate at European level, yet at the same time deliver results to the national policy makers.

The three example projects organized during the PACTIA project have provided insights on three of the grand challenges that our societies will face in the coming decades. The approaches made available through technology assessment has produced important input for policy makers and also demonstrated the important role that institutions for technology assessment can play at the national and the European level. Experiences from these three projects highlight especially two methods that work well on the cross-European level: citizen summits and scenario workshops. Having a common starting point (information material or futureoriented scenarios) in national activities gives the approach a common thematically starting point, but it also allows room for the cultural and social differences in countries and regions. This also produced output that is valuable for national, regional and European policy makers.

\section{Final words: making an impact}

In the end, the goal of TA is to make an impact on policy making. And its 'impact' can be manifold. It can contribute to bringing new or independent knowledge to science and technology themes or to the related societal aspects in policy-making processes; it can contribute to agenda setting; it can act as a mediator or facilitator between stakeholders; or it can lead to new policies or regulations being made (Decker and Ladikas, 2004). 
Even though some institutions have formal relationships with important policy makers, these policy makers are not demanded to act upon the advice coming from the TA community. One of the main characteristics of TA is its way of bringing together knowledge from a broad group of actors into the production of independent and well-grounded policy advice. By using existing as well as by further developing traditional methods, the TA community should strive to enhance evidence-based policy making at the national, regional and European levels.

The developments and discussions related to science, technology and society move forward with increasing pace. In order to advise policy makers on these developments as they unfold, TA institutions must be present and in contact with their target groups at all levels. Seeing that these developments happen on a European level and an international level, the need for cross-European TA is evident. Cross-border knowledge exchange and learning is highly relevant for policy makers in our societies today, and cross-European TA represents one way of making this happen.

Case studies based on the following projects:

- Energy transition in Europe (2007)

- Genetically modified plants and foods (2009)

- ICT and privacy in Europe (2006)

- Energy transition in Europe (2007)

- Genetically modified plants and foods (2009)

- ICT and privacy in Europe (2006)

- Challenges of Biomedicine (2007)

- CIVISTI (2011)

- Meeting of Minds (2006)

- Study on Human Enhancement (2009)

- Nanosafety (2011)

- Technology Options in Urban transport (2011)

- PACITA example projects: Personal Health Genomics, the future of ageing and sustainable consumption (2013-15)

\section{Notes}

1 For example, EUROPTA (2001) and the TAMI project (2004).

2 Examples from the case studies include 'Energy transition in Europe' (2007), 'Genetically modified plants and foods' (2009) and 'ICT and privacy in Europe' (2006). 
3 Examples from the case studies include 'Challenges of Biomedicine' (2007), 'CIVISTI' (2011) and 'Meeting of Minds' (2006).

4 Examples from the case studies include 'Study on Human Enhancement' (2009), 'Nanosafety' (2011) and 'Technology Options in Urban transport' (2011).

5 Information material and short films for the citizen summit, as well as scenarios in the scenario workshops.

(c) (i) Except where otherwise noted, this work is licensed under a Creative Commons Attribution 4.0 Unported License. To view a copy of this license, visit https://creativecommons.org/version4 